East African Medical Journal Vol. 77 No. 11 November 2000

SAFE MOTHERHOOD INTERVENTION STUDIES IN AFRICA: A REVIEW

M. Luck, DSc, Researcher, Centro de Malária e Outras Doenças Tropicais, Instituto de Higiene e Medicina Tropical, Universidade Nova de Lisboa, P-1300 Lisboa, Portugal

\title{
SAFE MOTHERHOOD INTERVENTION STUDIES IN AFRICA: A REVIEW
}

\author{
M. LUCK
}

\begin{abstract}
Objective: To review the findings of safe motherhood intervention studies conducted in African settings.

Data sources: Published literature regarding interventions designed to reduce maternal mortality in African settings.

Study selection: Studies conducted in sub-Saharan Africa to assess the effects of interventions designed to reduce maternal mortality.

Data extraction: Search of Medline database for the years 1988 to 1998 with additional manual search of references cited in Medline-referenced studies.

Data synthesis: Few of the 34 intervention studies identified used a double-blind, randomized controlled trial design (4/34), or outcome measures directly related to maternal mortality or maternal health (7/34). Six of the studies produced reasonably convincing evidence of a positive effect on maternal health outcomes. Of these, three showed that changes in delivery practices brought about improved maternal outcomes, two found that a combined intervention consisting of upgrading of emergency obstetric services and community education increased the number of major obstetric complications treated, and one showed that a range of improvements in hospital equipment and management reduced facility-based maternal mortality ratios. No study sought to reduce maternal mortality associated with unsafe termination of pregnancy.

Conclusions: More than a decade after the launching of the Safe Motherhood Initiative, there exists little evidence regarding which interventions will reduce maternal mortality levels in African settings. Intervention studies conducted in Africa have identified several low-tech improvements in emergency obstetric services which improve maternal outcomes and deserve replication and testing in a variety of settings. Further operational research should be conducted to identify and test other promising safe motherhood interventions, in particular interventions designed to reduce the important proportion of maternal mortality associated with unsafe termination of pregnancy.
\end{abstract}

\section{INTRODUCTION}

It is estimated that 150,000 African women die each year from causes related to pregnancy and childbearing, and that the lifetime risk of dying from maternal causes for African women is in the order of one in twenty five(1). Numerous descriptive epidemiology studies have documented levels and immediate causes of maternal mortality in various African settings(1), and for more than a decade there has been strong international consensus that these high mortality rates must be reduced(2). But which interventions are likely to bring about this result? Which interventions have been tested; which have been effective?

This article seeks to address these questions by reviewing published studies which examined the impact of safe motherhood interventions conducted in African settings. It outlines the search strategy used to identify the studies, gives an overview of the study designs and outcome measures, and describes the main findings. In a final section, recommendations are made based on the findings of the review.

\section{MATERIALS AND METHODS}

The initial source for the review was the Medline index for the years 1988 to 1999 when this review was conducted. A search using the terms "maternal mortality" and "Africa" yielded more than 600 records; these were culled by omitting non-epidemiologic materials (case studies and editorials). Review of the full text of the most relevant materials revealed additional reports. In all, 188 papers describing epidemiologic studies of maternal mortality in Africa were identified. Of these, just 34 were found to examine the effects of maternal health interventions. The paucity of published reports on maternal intervention studies in Africa is underscored by the fact that $24(71 \%)$ of the 34 identified studies were part of a single Carnegie and MacArthur Foundation funded project, the Prevention of Maternal Mortality Network(3). 


\section{RESULTS}

Study design: None of the 34 identified studies used a double-blind randomised controlled trial design, which is recognised as the "gold standard" for intervention studies and provides the soundest basis for inference about intervention effects. Four studies used a randomised trial design(4-6), but did not blind investigators or trial participants. The remaining 30 studies used less rigorous quasi-experimental designs such as "one-group pretest post-test" and "pretest post-test using a control group."

Outcome measures The measurement problems in assessing the impact of safe motherhood interventions have been well-documented $(8,9)$, and were reflected in the sub-optimal outcome measures used by nearly all the studies in this review. Maternal mortality is rare, even in populations with high maternal mortality ratios; thus extremely large sample sizes are needed to document statistically significant differences. Maternal morbidity is more common but, like other kinds of morbidity, is difficult to measure reliably(10). Facility-based maternal intervention studies face the additional challenge of establishing that observed changes reflect actual improvement in maternal health in the population, and not just changes in the case-mix seen at the facility. Similarly, data on the number of obstetric interventions performed are of limited utility if the indications for those interventions are not recorded, since observed changes may reflect shifts in the number of severe obstetric cases seen or in professional criteria for intervention.

Just two studies used maternal mortality ratios as a principal outcome measure, but neither was able to establish definitively that the observed improvements were the result of the study intervention. The maternal mortality ratios in one study were facility-based; thus the improvement observed could have reflected in a proportional increase in use of the facility by women with non-complicated deliveries rather than the positive effect of the intervention studied(11). The second study found a decline in maternal mortality ratios in communities where an intervention had been implemented, but noted this change could have been due to causes not associated with the intervention(12).

Only five studies used outcome measures directly related to maternal health, such as incidence of uterine rupture, mean duration of labour, or incidence of maternal hospital admissions(4,13-16). It is not known to what extent and to which improvements in these measures correspond to reductions in maternal mortality.

Thirteen of the studies(17-29) documented the number of women with severe obstetric complications treated at health facilities equipped to provide major obstetric interventions, since this information is easier to obtain than data on maternal mortality or health outcomes. The authors justified this approach by arguing that provision of major obstetric interventions to women with severe obstetric complications is known to be one of the most effective ways of reducing maternal mortality, and that it is reasonable to assume that the underlying incidence of severe obstetric complications in a community remains relatively constant over a period of several years. Thus, they argue, an increase in the number of women with severe obstetric complications treated at hospitals can be used as a proxy for a number of maternal lives saved. Unfortunately, this apparently reasonable argument requires a number of assumptions, including that birth rates are stable; that standardised, reliable definitions of "severe obstetric complications" are used, and quality of care at the facility remains consistent. Furthermore, the absence of denominators for most studies using these measures makes it impossible to assess whether observed changes in the number of severe obstetric cases seen are statistically significant.

Eight studies(30-37) used only process indicators as outcome measures, and therefore were unable to draw conclusions about the effect of the interventions on maternal outcomes. These studies, for example, documented that a community loan fund or training programme was implemented, but failed to report any data related to the effect of these initiatives on maternal health.

Six studies, including three of the four randomised trials(5-7,38-40), used perinatal indicators as main outcome measures since the objective of the maternal interventions studied concerned birth outcomes rather than maternal health. These indicators included perinatal mortality rates and incidence of low birthweight.

\section{POINTS OF INTERVENTION}

Review of the effects of the interventions studied is facilitated by placing the interventions in the context of the conceptual framework developed by McCarthy and Maine to analyse the determinants of maternal mortality(41).

McCarthy and Maine described three steps to maternal death $(41,42)$. First, there must be a pregnancy, since a maternal death is by definition directly or indirectly related to pregnancy. Second, complications must develop. These complications may arise from a pre-existing condition aggravated by pregnancy, from the pregnancy itself, or from management of the pregnancy (including its termination). They may persist for months or last for just moments. Finally, there must be no effective treatment of the complications, due to the absence of medical intervention, or to inappropriate or insufficient intervention.

The explicit recognition of the steps to maternal death makes it clear that, to prevent maternal deaths, interventions must operate on one or more of the following points of intervention: prevent pregnancy; prevent the occurrence of complications of pregnancy; or prevent complications from resulting in maternal death. As shown in Table 1, none of the identified studies sought to prevent maternal mortality by preventing pregnancy. Two studies sought to prevent complications $(4,12)$. Twenty-six studies sought to prevent complications from resulting in maternal death(11,13-37). The remaining six studies examined perinatal outcomes $(5-7,38-40)$. 
Table 1

Study interventions classified by point of intervention and objective

\begin{tabular}{|c|c|c|}
\hline Point of intervention & Objective & Intervention studied \\
\hline Prevent occurrence of complications & prevent puerperal infection & $\begin{array}{l}\text { Train TBAs } \\
\text { antiseptic wipe of birth canal }\end{array}$ \\
\hline \multirow[t]{2}{*}{$\begin{array}{l}\text { Prevent complications from } \\
\text { resulting in death }\end{array}$} & $\begin{array}{l}\text { reduce delay between onset of } \\
\text { complication and arrival } \\
\text { at hospital }\end{array}$ & $\begin{array}{l}\text { train community motivators } \\
\text { mass communication campaign } \\
\text { create ambulance service } \\
\text { establish fuel fund } \\
\text { establish community loan fund } \\
\text { improve transfer procedures } \\
\text { establish maternal waiting homes }\end{array}$ \\
\hline & improve quality of care at hospitals & $\begin{array}{l}\text { active management of labour } \\
\text { training aides to perform Caesarean section } \\
\text { upgrading facilities } \\
\text { establish revolving drug fund } \\
\text { establish blood bank } \\
\text { upgrade }+ \text { improved management of staff } \\
\text { and patients }\end{array}$ \\
\hline Improve perinatal outcomes & $\begin{array}{l}\text { prevent and treat maternal infection } \\
\text { reduce incidence of Caesarean section }\end{array}$ & $\begin{array}{l}\text { malaria chemoprophylaxis } \\
\text { syphilis screening and treatment } \\
\text { trial of labour for previous Caesarean section }\end{array}$ \\
\hline
\end{tabular}

No study identified in this review sought to assess the impact of antenatal interventions on maternal mortality. This may be due to the difficulties in establishing, even in industrialised countries, that standard antenatal practices improve maternal health(49). In fact, a recent review of the effectiveness of antenatal care noted a "striking" lack of evidence about the aetiology of common complications in pregnancy, as well as the biological efficacy of many treatments currently in use(49). The findings are described here according to the classification system shown in Table 1.

\section{PREVENT THE OCCURRENCE OF COMPLICATIONS}

The present literature review identified two studies which tested interventions designed to prevent puerperal sepsis. One examined the effect of training traditional birth attendants in clean delivery practices, while the second evaluated the effect of antiseptic wipe of the birth canal during delivery in hospital.

Greenwood et al (12) conducted a community-based study in rural Gambia to assess the effects of training of traditional birth attendants. They compared maternal and neonatal mortality rates before and after intervention in 15 villages where traditional birth attendants (TBAs) were trained and 26 smaller villages where TBAs were not trained. Maternal mortality ratios fell significantly in both sets of villages following intervention, and the difference between the treatment and control village rates was not statistically significant. By contrast, neonatal mortality rates declined in the treatment villages but not in the control villages. The study authors acknowledged that their study could not establish that the improved maternal outcomes observed during the study period were due to the TBA training, and not to factors such as improved transportation.

Taha et al (4) conducted a facility-based controlled trial to assess the effect of antiseptic wipes on maternal and birth outcomes for deliveries in an urban hospital in Malawi. The results of the trial showed that the antiseptic wipe was associated with declines in the rates of maternal hospital admissions due to delivery and postpartum infections. Maternal mortality did not change significantly during the study, but the study had not been designed to assess this. Regarding birth outcomes, the intervention was associated with a significant decrease in neonatal mortality, neonatal mortality due to sepsis, and neonatal hospital admission rates. The design of the Taha et al(43) study was questioned in a commentary paper whose author argued that possible sources of bias had not been sufficiently controlled. The main criticisms concerned the exclusion of large number of deliveries from the study and the fact that a number of the study's outcome measures are difficult to assess reliably; variations in the standards used for exclusion or outcome classification could have masked or exaggerated true effects.

\section{PREVENT COMPLICATIONS FROM RESULTING IN DEATH}

Twelve studies examined interventions designed to reduce the delay between the onset of serious complications of pregnancy and the arrival of the patient at hospital. The 
strategies were intended to reduce delay in the decision to seek care or to reduce delay in arriving at the hospital once the decision to seek care has been taken. The specific strategies used were: education of community members regarding the symptoms of serious complication, establishment of transport systems and loan funds, creation of maternal waiting shelters and improvement transfer procedures at primary health facilities.

Four studies examined the effect of interventions designed to increase community awareness of obstetric complications. In three cases, the referral health facility was upgraded prior to the community education campaigns.

Community educators and facilitators were the focus of two studies in Nigeria and one in Sierra Leone which sought to increase the number of women with major obstetric complications seen in hospital. None of these studies showed a large impact on utilisation of emergency obstetric care. In one study, the number of women with obstetric complications referred from the study communities increased from seven to 19 per year(18). In another just 18 women with obstetric emergencies were referred during 18 months of implementation in another study(22). In the third, the number of complications seen at a primary health unit increased from nine to only 16 per month(21). Due to lack of denominators, it is not possible to assess whether the relatively small changes observed are statistically significant.

A different approach to community education was examined in a Nigerian study(17). In this case, community education was accomplished through mass communication such as community meetings, pamphlets, posters and video shows. The study results indicated that community knowledge regarding obstetric complications had increased, but that this increase was not matched by an increase in the number of patients using emergency obstetric services. In fact, the number of severe obstetric complications cases referred declined from 234 to 136 during the study.

Seven studies tested interventions designed to reduce delay in reaching hospital once a decision to seek care had been made. Three of these sought to overcome financial obstacles by establishing community loan funds for emergency obstetric care(19,30,37). Two studies focussed on transport, through an ambulance programme or fuel fund $(20,36)$. Two studies examined the effect of maternal waiting shelters $(31,38)$.

Two studies in Nigeria and one in Sierra Leone examined the effect of establishment of community loan funds to support obstetric transportation and care. One Nigerian study documented important levels of use of the funds, with 380 women receiving loans and a $93 \%$ repayment rate, but did not measure the number of women with major obstetric complications seen at hospital(30). The second Nigerian study found that 18 loans were granted, but also neglected to assess the impact of the loans on use of emergency obstetric services in hospital(37). The third study, conducted in Sierra Leone, found that the annual number of emergency obstetric referrals increased from five to 12 in two chiefdoms with loan funds(19).
Three studies tested interventions to reduce travel time to hospital. Two of these studies were communitybased, and one concerned transfer from peripheral to referral facilities. In a study conducted in Sierra Leone, the creation of an ambulance service was found to increase the number of cases of major obstetric complications seen at hospital from an average of 0.9 per month to 2.6 per month, and reduced case fatality rates from $20 \%$ to $10 \%$ (20). Another study showed that 29 women with obstetric complications were transported to hospital after a revolving fuel fund was created for private drivers(36). Balde and Bastert studied the effect of improved transfer management procedures at peripheral health units in Guinea and found that the incidence of uterine rupture declined from $20 \%$ to $12 \%$ after intervention(14).

Two studies focussed on reducing delay in receiving emergency care through establishment of maternal waiting homes (residential facilities located near hospital where pregnant women identified as being "at risk" can stay until delivery). The success of this strategy depends principally on two factors: the sensitivity of the screening test used to refer pregnant women to maternal waiting homes and compliance among the identified women(44). Neither of the two studies examining this approach produced convincing evidence that maternal waiting homes have a positive impact on maternal outcomes. One study conducted in Ghana(31) found that a maternal waiting home was used by only one of the 25 women referred, and for just one night. The authors concluded that financial and personal hardships associated with staying away from home outweighed the perceived benefit of the homes in the study setting. A second study, conducted in Zimbabwe(38), found that 280 women had used maternal waiting homes, and that incidence of low birthweight was lower among births to these women than to women who had not used the homes. However, as the authors did not provide a plausible mechanism by which maternal waiting homes can affect birthweight, it is not possible to attribute this difference to the intervention.

Fourteen studies examined the effect of improved quality of care at hospital on the number of complications seen and on maternal outcomes. The specific interventions studied include active management and trial of labour, training of medical aides to perform Caesarean section, upgrading of facilities (equipping operating theatres, establishing blood banks), and a combination of upgrading and improved management of hospitals.

De Groof et al(13) compared maternal and birth outcomes for women who delivered before and after use of partograms was introduced in a maternity clinic in urban Niger. The study included data on 1299 deliveries by women who arrived at the clinic with dilation less than $4 \mathrm{~cm}$ and who did not have any of a long list of risk factors such as multiple pregnancy, breech presentation, hypertensive disorders of pregnancy, anaemia, haemorrhaging, and small stature. The study found that use of the partogram significantly reduced mean duration of labour, and increased use of anti-spasmodics, oxytocics and artificial rupture of membranes. 
Seven studies examined the combined effects of upgrading of facilities and community education campaigns on the number major obstetric complications treated. Of these, five were unable to demonstrate a sustained positive effect of the interventions(23-27), and two documented important increases in the number of major obstetric interventions performed $(28,29)$.

Four of the studies that failed to find a positive effect were conducted in Nigeria. $\operatorname{Two}(23,24)$ found that the number of major obstetric complications treated at upgraded hospitals increased after intervention, but that the increase was not sustained. Another two documented declines in the number of women with major obstetric complications seen at the upgraded hospitals $(25,26)$. In one case, this decline occurred despite an important increase in the number of deliveries seen annually from 325 to 1,952(2). The fifth study, which was conducted in Ghana, found that an average of nine major obstetric emergencies were seen and referred annually in a newly-established health centre, but did not assess whether this led to improved maternal outcomes or increased the number of major obstetric interventions(27).

Two studies which documented positive effects which the authors attributed to the combined upgrading and community education interventions. A study conducted in Sierra Leone found that the number of major obstetric complications seen annually at the upgraded hospital increased from 31 to 98 , and that the case fatality rate among these patients decreased from $32 \%$ to $5 \%(28)$. The second study, conducted in Ghana, found that the number of women with obstetric complications seen annually at the upgraded health center increased from 26 to 73 and that the number of obstetrical surgical procedure performed increased from 23 to 90(29). The absence of denominators for the data on number of complications treated means that the statistical significance of these increases cannot be calculated.

Two studies examined the effects of establishment of blood banks, since lack of blood for transfusion was identified as a problem in the facilities concerned. One, conducted in Nigeria, showed that the number of transfusions given annually at a small hospital increased from three to 17 following establishment of a blood bank(35). The second study, conducted in Sierra Leone, showed that refurbishment of a hospital blood bank and other improvements in obstetric services resulted in an increase in the annual number of transfusions from 296 to 452 , and a decrease in the case fatality rate for major obstetric interventions from $13 \%$ to $9 \%$ (34).

One study documented the effects of a drug cost recovery system implemented in Sierra Leone. The system was implemented because there had been shortages of essential drugs for use in obstetric emergencies at the facility studied. The authors found that purchasing drugs from a commercial source and managing them through the standard district system eliminated drug shortages(33), but did not assess the impact of this change on maternal outcomes.
Training and performance of non-medical staff was the focus of two studies. One conducted in Nigeria, showed that training of medical aides brought about increased knowledge about obstetric complications. The study authors did not assess whether the increased knowledge led to improved practices or better maternal outcomes(32). A more rigorous study conducted in Mozambique compared outcomes for patients whose Caesarean deliveries were performed by medical aides to those for patients whose Caesarean deliveries were performed by obstetrics and gynaecology specialists. The retrospective study found no differences in indications for Caesarean section among 958 patients seen by medical aides compared to 1113 patients seen by specialists, and that incidence of post-operative complications and the duration of hospital admissions were essentially the same in the two groups(15).

One study examined the effects of a range of 22 interventions related to quality of maternal care at a Tanzanian hospital(11). It found that upgrading of the hospital and improving personnel and patient management was associated with a reduction from 849 to 275 per 100,000 live births in the hospital-based maternal mortality ratio. However, as noted by the study authors, it was not possible to establish conclusively whether this decline was due to the interventions or to changes in the case mix seen at the facility.

\section{IMPROVE PERINATAL OUTCOMES}

Four studies examined maternal health interventions intended principally to improve birth outcomes, rather than maternal outcomes. Three of the studies tested the effect of malaria chemoprophylaxis and treatment of birthweight and perinatal mortality(5-7), and one tested the effect of a syphilis screening programme on birth outcomes(39).

In the Gambia, Greenwood et al(6) compared birth outcomes for rural women randomised to receive either Maloprim (100 mg dapsone $+25 \mathrm{mg}$ pyrimethamine) or placebo once fortnightly during pregnancy. The results of the trial found no significant differences in anaemia, parasitaemia or birth outcome between the 531 treated women and the 518 controls. However, the results of stratified analysis indicated that, among primagravidae, chemoprophylaxis reduced maternal anaemia and parasitaemia, and reduced the incidence of low birthweight. Among multigravidae, prophylaxis reduced parasitaemia but failed to have a significant effect on haemoglobin levels or birthweight. The study failed to find a significant difference for stillbirth, neonatal and perinatal mortality rates between the chemoprophylaxis and placebo groups.

Cot et al(5) conducted a similar randomised trial in Burkina Faso. In their study, 745 pregnant women received $300 \mathrm{mg}$. of chloroquine sulphate weekly, and 719 received no treatment. The results indicate that prophylaxis prevented placental infection, but had no important effect on birthweight. 
Steketee et al(7) conducted a large-scale randomised trial to examine the effect of alternative forms of malaria chemoprophylaxis on pregnancy outcomes in Malawi. As part of the trial, the birthweight and gestational age of 1766 live-born singletons were recorded, and a variety of risk factors for low birthweight assessed. The study found that, after controlling for 16 first birth, female gender of infant, low maternal weight, maternal syphilis and maternal HIV infection, use of an effective anti-malarial was protective against low birthweight. However, the study was not able to document a significant effect of antimalarial therapy on perinatal mortality.

Hira et al(39) examined a syphilis screening and treatment intervention implemented in peri-urban Lusaka in Zambia. As part of the study, three health centres undertook a health education campaign promoting early antenatal attendance and also revitalised their syphilis screening and treatment programmes for antenatal clinic attenders. Three comparison health centres included in the study continued to provide normal services. Study results showed that syphilis sero-reactivity was $8 \%$ among antenatal clinic attenders, and that $58 \%$ of syphilitic pregnancies had adverse outcomes, compared to $10 \%$ of non-syphilitic pregnancies. Following intervention, poor pregnancy outcomes were experienced by a smaller proportion of sero-reactive women from the treatment health centres than from the comparison centres $(28.3 \%$ versus $72.4 \%, \mathrm{p}<.001)$. Interestingly, despite their participation in the study, the intervention centres failed to achieve adequate levels of screening and treatment. Just $59 \%$ of antenatal attenders were screened, and just $46 \%$ of those found sero-reactive were treated. This finding suggests that considerable resource, organisational, or logistical barriers to implementation of adequate screening remained.

A study in Maputo Central Hospital compared perinatal outcomes before and after adoption of a policy to consider trial of labour for pregnant patients with one pervious Caesarean section(40). The study found that $53 \%$ of patients with one previous Caesarean were able to deliver vaginally, and that the perinatal mortality rate for these deliveries was lower than the overall hospital perinatal mortality rate; however this difference was not statistically significant.

\section{CONCLUSIONS}

The most striking finding of this literature review is how little conclusive evidence exists on the impact of safe motherhood interventions in Africa. Planners and policy makers seeking guidance about which interventions can improve maternal outcomes in African settings must in most cases either assume that findings from other regions are applicable in Africa, or rely on anecdotal reports.

Studies with evidence of impact: Just nine studies $(4,6,7,11,13,15,28,29,39)$ were able to produce reasonably convincing evidence that the interventions studied had a positive impact on maternal health outcomes. Three of these studies concerned perinatal outcomes, with two showing that malaria prevention and treatment during pregnancy is likely to have a small positive impact on birthweight $(6,7)$, and a third demonstrating that a health centre-based syphilis screening and treatment can improve perinatal outcomes(37). The remaining six studies concerned maternal outcomes.

Of the six studies of maternal outcomes, four were facility-based and two combined facility based and community-level interventions. Three studies showed that inexpensive changes in delivery practices (use of a partogram, antiseptic wipe of the birth canal, and training of medical assistants to perform Caesarean sections) can bring about improved maternal outcomes $(4,13,15)$. Another showed that a range of improvements in hospital equipment and management can reduce facility-based maternal mortality ratios(11). Two studies found that a combination of upgrading of emergency obstetric services in hospitals and community education led to substantial increases in the number of major obstetric complications treated without an increasing case fatality rates $(28,29)$.

Prevention of maternal mortality network: An intriguing finding of this literature review is that just two of the twenty Prevention of Maternal Mortality (PMM) Network studies in this report were able to produce reasonably conclusive evidence that the interventions studied had a positive impact on maternal health outcomes. Analysis of possible causes of the disappointing results may offer guidance or be useful for those planning future studies of maternal mortality interventions.

The majority of the PMM network studies were carried out using similar methodology. Interventions were selected based on the belief that increased utilisation of emergency obstetric services by women experiencing severe obstetric complications will reduce maternal mortality, and on the results of focus group discussions on barriers to use of these services. The results of the focus group discussions indicated that lack of knowledge about symptoms of severe obstetric complications, transport problems and hospital fees were the major barriers to increased use of emergency obstetric services; thus community-level interventions were designed to overcome these barriers. Prior to implementing these interventions, hospital obstetric wards and operating theaters were "upgraded," generally through purchase or refurbishing of equipment, and occasionally by arranging for additional staff. As noted above, in most cases, this combination of interventions failed to have a large positive effect on utilisation of emergency obstetric services.

Why did most PMM interventions result in no or minor improvements in maternal outcomes? One possible explanation is that neither problem analysis nor implementation of interventions fully considered the broader health system in which obstetric emergencies occur. For example, the study teams identified obstacles to utilisation of obstetric emergency services not by undertaking a multi-source analysis of usage patterns in the context of specific local cultural, economic and social conditions, but by merely asking groups why obstetric 
services are not used. Similarly, "upgrading" of health facilities was done without first exploring the specific resource, management and procedural constraints (as viewed by staff and patients) in each hospital. This narrow focus may explain why two PMM studies with more comprehensive sets of interventions $(28,29)$ and the Mbaruku and Bergstrom study, which evaluated the effects of 22 interventions(11), had better results than majority of the PMM studies.

Conspicuously absent were interventions to prevent unsafe abortion: No study identified in the present literature review explicitly sought to prevent maternal morbidity and mortality caused by unsafe abortion, despite the growing evidence that unsafe abortion is responsible for a large proportion of maternal deaths in Africa. A recent review of literature on unsafe abortion found estimates of the contribution of unsafe abortion to maternal mortality as high as $54 \%$ (45 cited in 46 ), while a multi-centre study estimated that $30 \%$ of maternal deaths in Lesotho, Malawi, Uganda and Zambia were due to unsafe abortion(47).

It is likely that legal issues are the principal reason that Safe Motherhood programmes have largely neglected this important cause of maternal death. Abortion laws in many African countries are restrictive(45), and public health practitioners may be hesitant to take on the role of legal or political advocates. Yet medical professional working in clinical settings in African are generally well aware both of the important demand for safe induced abortion, and of the public health consequences of the widespread failure to meet this demand.

\section{RECOMMENDED STRATEGIES FOR FUTURE STUDIES}

The results of this literature review suggest a number of strategies for future Safe Motherhood intervention studies:

(i) Design issues: It is unlikely that sufficient funding will be available to conduct double-blind, randomised controlled trials of the large number of possible maternal health interventions; thus researchers must seek ways to enhance the strength of findings of less expensive, but also less conclusive, quasi-experimental designs. Tracking trends before and after intervention in treatment and control groups is perhaps the strongest quasi-experimental design, but cannot eliminate all possible important sources of bias. Triangulation, in which quantitative and qualitative data from multiple sources in health facilities and the community are used to confirm principal study results, may be the best way to overcome necessary weaknesses in study design;

(ii) Measurement issues: Few intervention studies are likely to be large enough to detect significant differences in maternal mortality ratios during study intervention; thus alternative outcome measures must be sought. Number of cases of severe obstetric complications treated in health facilities is one measure likely to be associated with maternal mortality ratios, but must be used carefully to ensure that classification of cases is reliable. Recent work in measuring "unmet obstetric needs" by De Browere et al.(48) has made advances in this area. Duration of labour or of maternal admissions are other useful outcome measures if care is taken to document that definitions and standards used are reliable and;

(iii) Interventions: Given the dearth of evidence regarding the ability of antenatal programmes to prevent maternal complications(49), the focus of safe motherhood research should be on identifying ways to increase the quantity and quality of emergency obstetric care received by women with obstetric complications. Promising interventions in this area include improved management of labour through use of the partograph, oxytocics and surgical interventions. Improvement in the quality of overall obstetric care provided by hospitals may lead to enhanced utilisation of these facilities, but the nature of this relationship is a function of the local health systems. Promising interventions include regular audit-oriented meetings, provision of on-the-job training, improved scheduling of staff to ensure 24hour coverage, establishment of norms for patient management, and training of nurses or medical aides to perform some tasks previously done by medical specialists.

Community or primary-level interventions may have smaller effects than facility-based improvements, but may contribute to reduced maternal and perinatal mortality. Little is known about community-level antenatal screening. It is possible that interventions such as checking for oedema, hypertension, or transverse or oblique lie may be feasibly and effectively accomplished by lay persons. Similarly, improved understanding of the determinants of noncompliance with referral advice may lead to development of interventions to address this problem. Antenatal screening programmes often fail to identify and treat women with risk factors $(37,50)$, thus improvements in antenatal services may be a promising area for intervention. Syphilis screening and treatment of all pregnant women is one of the most promising interventions to reduce perinatal mortality $(37,49)$, and will have a positive impact on maternal morbidity.

Provision of safe abortion services is likely to be among the most effective safe motherhood interventions, since the complications of unsafe abortion cause $30-50 \%$ of maternal deaths in some settings(45-47). It is wellrecognised that many induced abortions are performed in health facilities in countries where legal restrictions on abortion exist; interventions to make these services safer and more accessible would be likely to reduce maternal mortality. The potential of this kind of intervention is illustrated by one study conducted in a country in which abortion is illegal reported a sharp increase in the number of induced abortions performed in a hospital following staffing and equipment upgrades (29). 


\section{HEALTH SYSTEMS APPROACH}

It is well recognised that pregnancy, complications of pregnancy, and obstetric emergencies occur within the larger context of the local health system(1,50). Local knowledge about pregnancy, the aetiology of maternal morbidity, and appropriate therapies for these conditions influence how and why formal health services are utilised, but is often ignored in maternal health intervention studies. Similarly, the complex web of personal, economic and political factors affecting the provision of maternal health services are generally ignored, and installation of equipment or posting of additional staff considered sufficient remedies for the inadequate quality of care provided in many health facilities. To succeed, future studies of maternal health interventions must take broader, systems approach. Analysis of problems and implementation of interventions should take into account a wider range of factors and use multiple data sources to document both existing systems and how these systems respond to intervention.

\section{ACKNOWLEDGEMENTS}

I gratefully acknowledge the support and assistance of Paulo Ferrinho and Virgllio do Rosario. Thanks to Agosto Cardanha and Isabel Andrade for provision of many of the bibliographic materials. This paper is dedicated to Maria Joao Covas.

\section{REFERENCES}

1. AbouZahr C. and Royston, E. Maternal Mortality, a Global Factbook. World Health Organization, Geneva, 1991.

2. Starrs, A. Preventing the Tragedy of Maternal Deaths: a Report on the International Safe Motherhood Conference. Nairobi, Kenya, February, 1987.

3. The Prevention of Maternal Mortality Network. Situation analyses of emergency obstetric care facilities: examples from eleven sites in West Africa. Soc. Sci. Med. 1995; 40:657-667.

4. Taha, T.E., Biggar, R.J., Broadhead, R.L., Mtimavalye, L.A.R., Justesen, A.B., Liomba, G.N., Chiphangwi, J.D., et al. Effect of cleansing the birth canal with antiseptic solution on maternal and newborn morbidity and mortality in Malawi: clinical trial. Brit. Med. J. 1997; 26:216-219

5. Cot, M., Roisin, A., Barro, D., Yada, A., Verhave, J.-P., Carnevale, P.et $\mathrm{al}$. Effect of chloroquine chemoprophylaxis during pregnancy on birth weight: results of a randomized trial.Amer. J. Trop. Med. Hyg 1992; 46:21-27

6. Greenwood, B.M., Greenwood, A.M., Snow, R.W., Byass, P., Bennett, S., and HatibN'jie, A.B. The effects of malaria chemoprophylaxis given by traditional birth attendants on the course and outcome of pregnancy. Trans. roy. Soc. Trop. Med. Hyg. 1989; 83:589-594

7. Sketekee, R.W., Wirima, J.J., and Campbell, C.C. The effect of malaria and malaria prevention in pregnancy on offspring birthweight, prematurity, and intrauterine growth retardation in rural Malawi. Amer. J. Trop. Med. Hyg. 1996; 55:33-41.

8. Graham, W.J. and Campbell, O.M. Maternal health and the measurement trap. Soc. Sci. Med. 1992; 35:967-977;

9. Graham, W.J., Filippi, V.G.A., and Ronsmans, C. Demonstrating programme impact on maternal mortality. Health Policy Plan. 1996; 11:16-20.

10. Ronsmans, C., Achadi, E. Cohen, S. and Zazri, A. Women's recall of obstetric complications in South Kalimantan, Indonesia. Stud. Fam. Plann. 1997; 28:203-214.
11. Mbaruku, G. and Bergstrom, S. Reducing maternal mortality in Kigoma, Tanzania. Health Policy Plan. 1995; 10:71-78.

12. Greenwood, A.M., Bradley, A.K., Byass, P., Greenwood, B.M., Snow, R.W., Bennett, S. et al. Evaluation of a primary health care programme in The Gambia. I. The impact of trained. birth attendants on the outcome of pregnancy. J. Trop. Med. Hyg. 1990; 93: 58-66

13. De Groof, D., Vangeederhuysen, C., Juncker, T. and Favi, R.A. Impact of the introduction of a partogram on maternal and perinatal mortality. Study performed in a maternity clinic in Niamey, Niger. Ann. Soc. Belge Med. Trop. 1995; 75:321-330.

14. Balde, M.D. and Bastert, G. Decrease in uterine rupture in Conakry, Guinea by improvements in transfer management. Int. J. Gynec. Obstet. 1990; 31:21-24.

15. Pereira, C., Bugalho, A., Bergstrom, S., Vaz, F. and Cotiro, M. A comparative study of caesarean deliveries by assistant medical officers and obstetricians in Mozambique. Brit. J. Obstet. Gynaecol. 1996; 103:508-512.

16. De Muylder, X. and Thiery, M. The impact of a strict new obstetrical strategy on maternal mortality and obstetrical results. Arch. Belg. 1989; 47:67-69.

17. Bello Gummi, F., Hassan, M., Shehu, D., and Audu, L. Community education to encourage use of emergency obstetric services, Kebbi State, Nigeria.Int J. Gynec. Obstet 1997;59,Suppl.2:S191S200.

18. Olaniran, N., Offiong, S., Ottong, J., Asuquo, E. and Duke, F. Mobilizing the community to utilize obstetric services, Cross River State, Nigeria. Int. J. Gynec. Obstet 1997; 59, suppl. 2:S181-S189.

19. Fofana, P., Samai, O., Kebbie, A., and Sengeh, P. Promoting use of obstetric services through community loan funds, Bo, Sierra Leone. Int. J. Gynec. Obstet 1997; 59, suppl. 2:S225-S230.

20. Samai, O. and Sengeh, P. Facilitating emergency obstetric care through transportation and communication, Bo, Sierra Leone. Int. J. Gynec.Obstet 1997; 59, suppl. 2:S157-S164.

21. Kandeh, H.B., Leigh, B., Kanu, M.S., Kuteh, M. Bangura, J., Seisay, A.L. et al. Community motivators promote use of emergency obstetric services in rural Sierra Leone. Int. J. Gynec. Obstet 1997; 59, suppl. 2:S209-S218.

22. Nwakoby, B., Akpala, C., Nwagbo, D., Onah, B., Okeke, V., Chukudebelu, W. et al. Community contact persons promote utilization of obstetric services, Anambra State, Nigeria. Int. J. Gynec. Obstet 1997; 59, suppl. 2:S219-S224.

23. Ande, B., Chiwuzie, J., Akpala, W., Oronsaye, A., Okojie, O., Okolocha, C. et al. Improving obstetric care at the district hospital, Ekpoma, Nigeria. Int. J. Gynec. Obstet 1997; 59,suppl.2:S47S53.

24. Oyesola, R., Shehu, D., Ikeh, A.T., and Maru, I. Improving emergency obstetric care at a state referral hospital, Kebbi State, Nigeria. Int. J. Gynec. Obstet 1997; 59, suppl. 2:S75-S81.

25. Sabitu, K., Alti-Mu'azu, M., Musa, A.A., Ifenne, D.I., Essien, E.S., Golji, N.G. et al. The effect of improving maternity services in a secondary facility, Zaria, Nigeria. Int. J. Gynec. Obstet 1997 ; 59, suppl. 2:S99-S106

26. Ifenne, D., Essien, E., Golji, N., Sabitu, K., Alti-Mu'aza, M., Musa, A. et al. Improving the quality of obstetric care at the teaching hospital, Zaria, Nigeria. Int. J. Gynec. Obstet 1997; 59, suppl. 2:S37-S46

27. Senah, K.A., Richardson, D., Kwofie, G., Wilson, J.B., Collison, A.H., and Tinkorang, E.K. From abandoned warehouse to lifesaving facility, Pakro, Ghana. Int. J. Gynec. Obstet 1997; 59, suppl. 2:S91-S97.

28. Djan, J.O., Kyei-Faried, S., Twum, S., Danquah, J.B., Ofori, M., and Browne, E.N. Upgrading obstetric care at the health center level, Juaben, Ghana. Int. J. Gynec. Obstet 1997; 59, suppl. 2:S83-S90. 
29. Leigh, B., Kandeh, H.B.S., Kanu, M.S., Kuteh, M., Palmer, I.S., Daoh, K.S. et al. Improving emergency obstetric care at a district hospital, Makeni, Sierra Leone. Int. J. Gynec.Obstet 1997; 59, suppl. 2:S55-S65.

30. Chiwuzie, J., Okojie, O., Okolocha, C., Omorogbe, S. Oronsaye, A., Akpala, W. et al. Emergency loan funds to improve access to obstetric care in Ekpoma, Nigeria. Int. J. Gynec. Obstet 1997; 59, suppl. 2:S231-S236.

31. Wilson, J.B., Collinson, A.H.K., Richardson, D., Kwofie, G., Senah, K.A. and Tinkorang E.K. The maternity waiting home concept: the Nsawam, Ghana experience. Int. J. Gynec. Obstet 1997; 59, suppl. 2:S165-S172.

32. Chukudebelu, W., Ikeme, A., Okaro, J., Eguciem, P., Onah, B., Okeke, V. et al.Involving the private sector in improving obstetric care, Anambra State, Nigeria. Int. J. Gynec. Obstet 1997; 59, suppl. 2:S107-S112.

33. Thuray, H. Samai, O., Fofana, P. and Sengeh, P. Establishing a cost recovery system for drugs, Bo, Sierra Leone. Int. J. Gynec. Obstet 1997; 59, suppl. 2:S141-S147.

34. Sengeh, P., Samai, O., Sidique, S.K., Kebbie, A., Fofana, P. and Stephens, S. Improving blood availability in a district hospital, Bo, Sierra Leone. Int. J. Gynec. Obstet 1997; 59, suppl. 2:S127S134.

35. Nwagbo, D., Nwakoby, B., Akpala, C. Chukudebelu, W., Ikeme, Al., Okaro, J. et al. Establishing a blood bank at a small hospital, Anambra State, Nigeria. Int. J. Gynec. Obstet 1997; 59, suppl. 2:S135-S139.

36. Shehu, D., Ikeh, A.T. and Kuna, M.T. Mobilizing transport for obstetric emergencies in Northern Nigeria. Int. J. Gynec.Obstet 1990; 31:21-24.

37. Essien, E., Ifenne, D., Sabitu, K., Musa, A., Alti-Mu'aza, M. and Adidu, V. Community loan funds and transport services for obstetric emergencies in northern Nigeria. Int. J. Gynec. Obstet 1997; 59, suppl. 2:S237-S244.

38. Tumwine, J.K. and Dungare, P.S. Maternity waiting shelters and pregnancy outcome: experience from a rural area in Zimbabwe. Ann. Trop. Paed. 1996; 16:55-59.
39. Hira, S.K., Bhat, G.J., Chikamata, D.M., Nkowane, B., Tembo, G., Perine, P.L.et al. Syphilis intervention in pregnancy: Zambian demonstration project. Genitourin. Med. 1990; 66:159-164.

40. Granja, A., Gome, E., Bugalho, A., Machungo, F. and Carlomagna, G. Management of labour following caesarean section in a developing country. Clin. Exp. Obstet. Gynecol. 1991; 18:47-50.

41. McCarthy, J and Maine, D. A framework for analyzing the determinants of maternal mortality. Stud. Fam. Plann. 1992; 23:23-33.

42. McCarthy, J. The conceptual framework of the PMM Network. Int. J. Gynec. Obstet. 1997; 59 suppl. 2:S15-S21.

43. Duley, L. Commentary: sources of bias must be controlled. Brit. Med. J. 1997; 26: 220.

44. Figa-Talamanca, I. Maternal mortality and the problems of accessibility to obstetric care: the strategy of maternal waiting homes. Soc. Sci. Med. 1996; 42:1381-1390.

45. Toure, B., Thonneau, P., Cantrelle, P., Barry, T.M., Njo-Khac, T., and Papiernik, E. Levels and causes of maternal mortality in Guinea (West Africa). Int. J. Gynec.Obstet 1992; 37:89-95.

46. Benson, J., Nicholson, L.A., Gaffikin, L. and Kinoti, S.N. Complications of unsafe abortion in sub-Saharan Africa: a review. Health policy Plan. 1996; 11:117-131.

47. Likwa R.N. Abortion: a risk factor to maternal mortality in East, Central and Southern Africa. Paper presented at MWIA Congress, Nairobi, Kenya, 28 November - December 3, 1993.

48. De Brouwere, V., Laabid, A. and Van Lerberghe, W. Quels besoins en interventions obstetricales? Une approche fondee sure l'analyse spatiale des deficits. Rev. Epidémiol. Santé Publique 1996; 44:124.

49. Rooney, C. Antenatal care and maternal health: how effective is it? A review of the evidence. Maternal Health and Safe Motherhood Programme, Division of Family Health, World Health Organization, Geneva, 1992.

50. Thaddeus, S. and Maine, D. Too far to walk: maternal mortality in context. Soc. Sci. Med. 1994; 38:1091-11 10.

51. Sauerborn, R., Nougtara, A., Sorgho, G., Bidiga, J., and Diesfeld, H.J. Assessment of MCH Services in the District of Solenzo, Burkina Faso. III. Effectiveness of MCH Services in Detecting and Caring for Mothers and Children at Risk. J. trop. Paediat. 1989; 35, suppl.:14-17 